\title{
Pengetahuan Remaja Anak Jalanan Tentang Bahaya Seks Bebas dan Penyakit Menular Seksual di Komunitas Peduli Anak Kelurahan Medan Maimun
}

\author{
Nur Asiah ${ }^{1, *}$, Nur Asnah Sitohang ${ }^{2}$, Dewi Elizadiani Suza $^{3}$ \\ ${ }^{1}$ Universitas Sumatera Utara, Fakultas Keperawatan, Jl. Prof. T. Maas No. 3, Medan, Sumatera Utara 20155, Indonesia \\ ${ }^{2}$ Universitas Sumatera Utara, Fakultas Keperawatan, Jl. Prof. T. Maas No. 3, Medan, Sumatera Utara 20155, Indonesia \\ ${ }^{3}$ Universitas Sumatera Utara, Fakultas Keperawatan, Jl. Prof. T. Maas No. 3, Medan, Sumatera Utara 20155, Indonesia \\ 1Email: asiahnur9478@gmail.com *; ${ }^{2}$ Email : sitohangnurasnah@gmail.com, ${ }^{3}$ Email : elizadiani@ hotmail.com \\ * corresponding author
}

ARTICLE INFO

Keywords

Street Children,

Health Cadres,

Sexually Transmitted Diseases,

Free Sex

\begin{abstract}
Reproductive health and adolescent understanding of the dangers of free sex and sexually transmitted diseases in Indonesia is still low, this can be seen from the many cases of pregnancy outside of marriage, dating violence and abortion with high-risk drugs. Adolescent's understanding of reproductive health is a provision for adolescents to behave in a healthy and responsible manner. Not all adolescents have received sufficient and correct information about reproductive health. Street children are a group of children who are on the side of the road or on the road, who carry out activities in the hope of earning money for life. Knowledge and attitudes towards personal hygiene of reproductive organs are also poor in terms of research results. Therefore they need to be given counseling, guidance and support, so that healthy growth and development can occur so that one day these teenagers will become healthy adults physically, spiritually and socially through the formation of health cadres. This community service is carried out on street teenagers in the Community Caring for Children (KOPA) Medan Maimun. Medan city. The methods used in this activity are: 1. Health education with material on adolescent reproductive health, the dangers of free sex behavior and sexually transmitted diseases; 2. Cadre training; 3 . Assistance of cadres in conducting counseling to peers (peer group). 4. Evaluation of the success of the program: post-test for outreach cadres and youth participants. The data analysis used was univariate. The number of respondents 25 people. The results showed that the majority of the Padang ethnic group (76\%), junior high school education (54\%), father and mother still (father $80 \%$ and mother 92\%), education of $80 \%$ high school parents. The results of the questionnaire on knowledge were still there $(44 \%)$ street children had not answered questions about the symptoms of HIV / AIDS. Symptoms of HIV / AIDS include fever, night sweats, continuous diarrhea, fatigue, and persistent coughing and weight loss. They also have not all answered correctly on the question of gangrene is a type of sexually transmitted infection (24\%), mode of transmission of sexually transmitted diseases (20\%); and HIV / AIDS can cause death $(20 \%)$. This is because young children have never received this information either at school or from their parents. Researchers suggest that the KOPA manager should actively cooperate with the nearest PUSKESMAS to provide information about the dangers of free sex and sexually transmitted diseases.
\end{abstract}

\section{Pendahuluan}

Seks bebas adalah segala tingkah laku yang didorong oleh hasrat seksual terhadap lawan jenis maupun sesama jenis yang dilakukan di luar hubungan pernikahan dan bertentangan dengan norma-norma tingkah laku seksual dalam masyarakat yang tidak bisa diterima secara umum. Seks bebas adalah segala cara mengekspresikan dan melepaskan dorongan seksual yang berasal dari kematangan organ seksual, seperti berkencan intim, bercumbu, sampai melakukan kontak seksual, tetapi perilaku tersebut dinilai tidak sesuai dengan norma karena remaja belum memiliki pengalaman tentang seksual [1]. Anak memperlihatkan minat mereka terhadap seks dengan membicarakannya dengan teman-teman bermain kalau tidak ada orang dewasa, dengan memperlihatkan gambargambar pria dan wanita dewasa dalam pose yang merangsang. 
Perkembangan masa anak-anak adalah masa meniru dan mencontoh apa yang dilihat dan didengar dari perbuatan orang disekitarnya apakah saudara, teman maupun orang tuanya. Memori anak yang masih kosong akan mudah dan cepat menirukanya. Anak memandang orang tua sebagai idola dan simbol kebanggaanya [2]. Pandangan remaja terhadap seks kian berubah. Remaja dengan sikap keserbabolehan, sebagian menganggap hubungan seks pranikah tidak perlu dipersoalkan. Hubungan seks pranikah umumnya berawal dari masa pacaran. Masa pacaran ini hubungan intim mulai dilakukan kalangan remaja. Waktu pacaran mereka melakukan cumbu rayu, peluk cium dan bila gejolak nafsu tidak terkendali berlanjutnya ke hubungan badan [3].

Perilaku seksual pranikah adalah kegiatanseksual yang melibatkan dua orang yang saling menyukai atau saling mencintai, yang dilakukan sebelum perkawinan. Seks bebas atau dalam bahasa populernya disebut extra-martial intercourse atau kinky-seks merupakan bentuk pembebasan seks yang dipandang tidak wajar [4]. Masalah seksual pada remaja timbul karena faktor-faktor perubahan hormonal yang meningkatkan hasrat seksual remaja; kecenderungan pelanggaran makin meningkat oleh karena adanya penyebaran informasi dan rangsangan seksual melalui media masa yang dengan adanya teknologi canggih (acara televisi, video kaset, DVD, HP, dan internet); pergaulan yang makin bebas antara pria dan wanita dalam masyarakat sebagai akibat berkembangnya peran dan pendidikan wanita sehingga kedudukan wanita makin sejajar dengan pria [3].

Kajian riset dan survei mengenai kesehatan reproduksi dan seksualitas anak muda di Indonesia oleh Badan Kependudukan dan Keluarga Berencana Nasional (BKKBN) mencatat hasil survei pada 2010 menunjukkan bahwa 51 persen dari total responden remaja di Jabodetabek telah melakukan seks pranikah. Hasil survei untuk beberapa wilayah lain di Indonesia, seks pranikah juga dilakukan beberapa remaja seperti Surabaya yakni 54 persen, Bandung 47 persen, dan 52 persen di Medan.

Data dari Komisi Perlindungan Anak Indonesia (KPAI) menyatakan sebanyak 32 persen anak muda usia 14 hingga 18 tahun di kota-kota besar di Indonesia (Jakarta, Surabaya, dan Bandung) pernah berhubungan seks. Hubungan seks yang dilakukan sebelum usia 17 tahun misalnya, risiko terkena penyakit bisa mencapai empat hingga lima kali lipat. Sejak tahun 2007 tedapat 2.947 kasus AIDS dan periode Juni 2009 meningkat hingga delapan kali lipat menjadi17.699 kasus. Dari jumlah tersebut, yang meninggal dunia mencapai 3.586 orang. Bahkan diestimasikan, di Indonesia tahun 2014 akan terdapat 501.400 kasus HIV/AIDS. Penderita HIV/AIDS sudah terdapat di 32 provinsi dan 300 kabupaten/ kota. Penderita ditemukan terbanyak pada usia produktif, yaitu 15-29 tahun usia anak muda masuk di dalamnya [5].

Penyakit kelamin (veneral disease) sudah lama dikenal di Indonesia. Dengan semakin majunya ilmu pengetahuan istilah tersebut sudah tidak digunakan lagi dan dirubah menjadi Sexually Transmitted Disease (STD) atau Penyakit Menular Seksual (PMS). Istilah STD berubah menjadi Sexually Transmitted Infection (STI) agar dapat menjangkau penderita asimptomatikSejak tahun 1998. Infeksi menular seksual (IMS) adalah infeksi yang ditularkan dari satu orang ke orang lainnya melalui hubungan seksual [9]. Infeksi menular seksual merupakan salah satu dampak perilaku seks bebas. Anak jalanan adalah sekelompok anak yang berada dipinggiran maupun dibadan jalan, yang melakukan aktivitas meminta-minta, ngamen, tukang lap-lap mobil atau aktivitas lainnya dengan harapan mendapat uang demi kehidupan. Anak banyak yang terpaksa meninggalkan sekolah guna mencari nafkah di jalan, sehingga anak jalanan di kota-kota besar meningkat jumlahnya [11]. Usia anak jalanan antara 5-18 tahun, banyak dari mereka yang penampilannya kusam serta pakaian yang tidak layak [19]. Data dan informasi kesejahteraan Kemensos (2017) menyatakan jumlah anak jalanan di Indonesia sebanyak 16.290. Berdasarkan Survey yang pernah dilakukan oleh PKPA atau Pusat Kajian dan Perlindungan Anak Kota Medan pada tahun 2011, ada beberapa Kecamatan yang mempunyai jumlah anjal (anak jalanan) lebih dari 50 anak per Kecamatan [12].

Kecamatan tersebut adalah Medan Johor populasinya sebanyak 57 Anak jalanan, Medan Amplas yaitu 81 anak jalanan, untuk Medan Kota terdapat anak jalanan sebanyak 94, dan ada 103 anak jalanan yang berada di Kecamatan Medan Maimun, untuk Kecamatan Medan Sunggal terdapat 75 anak jalanan, Medan Petisah sebanyak 60 anak dan Kecamatan Medan bagian deli sebanyak 53 anak. Kecamatan Medan Maimun merupakan salah satu tempat yang mempunyai 
populasi anjal paling tinggi. Berdasarkan hasil observasi yang sudah dilaksanakan sebelumnya, bahwa di Kecamatan Medan Maimun tepatnya di Kelurahan Aur adalah salah satu tempat dengan jumlah anak jalanan yang lumayan besar. Anjal yang berada di Kelurahan Aur Kecamatan Medan Maimun, mengalami masalah seperti anak jalanan pada umumnya yaitu, melakukan tindakan kriminal, melakukan kekerasan pada teman yang lebih lemah dan meminta atau merampas uang dengan cara memaksa serta memakai obat-obatan terlarang [12].

Anak jalanan diketahui memiliki pengetahuan dan sikap yang kurang karena keterbatasan informasi serta pendidikan yang mereka peroleh. Pengetahuan dan sikap personal hygiene organ reproduksi remaja putri jalanan di Kota Denpasar (2015) buruk dilihat dari hasil penelitian pengetahuan remaja putri jalanan tentang personal hygiene organ reproduksi mayoritas tergolong rendah 51,02\%. Remaja putri jalanan dalam kelompok umur 10-13 tahun memiliki pengetahuan yang rendah $57,14 \%$. Remaja putri jalanan yang tidak bersekolah memiliki pengetahuan yang rendah 66,67\%. [16].

\section{Metode}

Metode yang digunakan dalam pengabdian ini adalah dengan :1. Pendidikan kesehatan dengan materi kesehatan reproduksi remaja, bahaya perilaku seks bebas dan penyakit menular seksual; 2 . Pelatihan kader ; 3. Pendampingan kader melakukan penyuluhan kepada teman sebaya (peer group). 4. Evaluasi keberhasilan program: post test kader dan remaja peserta penyuluhan. Teknik pengambilan sampel adalah total sampling dan analisis data menggunakan distrubusi frekwensi.

\section{Hasil dan Diskusi}

3.1. Karakteristik anak jalanan

Tabel 1. Karakteristik remaja anak jalanan di Komunitas Peduli Anak Jalanan Kec. Medan Maimun $(n=25)$

\begin{tabular}{l|c|c}
\hline \multicolumn{1}{c|}{ Variabel } & F & $\%$ \\
\hline Suku & 19 & 76.0 \\
- Padang & 4 & 16.0 \\
- Batak Mandailing & 2 & 8.0 \\
- Melayu & 25 & 100.0 \\
Total & & \\
\hline Pendidikan & 14 & 54.0 \\
- SMP & 11 & 44.0 \\
- SMA & 25 & 100.0 \\
Total & & \\
& & \\
\hline Status Ayah & 20 & 80.0 \\
- Masih Hidup & 5 & 20.0 \\
- Sudah Meninggal & 25 & 100.0 \\
Total & & \\
\hline Status Ibu & 23 & 92.0 \\
- Masih Hidup & 2 & 8.0 \\
- Sudah Meninggal & 25 & \\
Total & & 8.3 \\
\hline Pendidikan Ayah & 1 & 80.0 \\
- SD & 2 & 100.0 \\
- SMP & 20 & \\
- SMA & 23 & \\
Total & & \\
& & \\
\hline
\end{tabular}




\begin{tabular}{l|c|c}
\hline Pendidikan Ibu & & \\
- SD & 1 & 4.3 \\
- SMP & 3 & 12.0 \\
- SMA & 18 & 72.0 \\
- S1 & 1 & 4.0 \\
Total & 23 & 100.0 \\
\hline
\end{tabular}

3.2. Hasil kuesioner pengetahuan remaja anak jalanan

Tabel 2. Distribusi frekwensi pengetahuan remaja anak jalanandi Komunitas Peduli Anak Jalanan Kec. Medan Maimun $(\mathbf{n}=25)$

\begin{tabular}{|c|c|c|c|c|c|}
\hline \multirow{2}{*}{ No. } & \multirow{2}{*}{ Pertanyaan } & \multicolumn{2}{|c|}{$\mathbf{Y a}$} & \multicolumn{2}{|c|}{ Tidak } \\
\hline & & $\mathbf{F}$ & $\%$ & $\mathbf{F}$ & $\%$ \\
\hline 1 & $\begin{array}{l}\text { Perilaku seks bebas tidak baik untuk kesehaatan } \\
\text { reproduksi remaja }\end{array}$ & 24 & 96 & 1 & 4 \\
\hline 2 & $\begin{array}{l}\text { Perilaku seks bebas adalah melakukan hubangna seksual } \\
\text { sebelum menikah }\end{array}$ & 23 & 92 & 2 & 8 \\
\hline 3 & $\begin{array}{l}\text { Contoh perilaku seks bebas adalah berciuman dengan } \\
\text { teman lawan jenis }\end{array}$ & 23 & 92 & 2 & 8 \\
\hline 4 & Dampak perilaku seks bebas adalah hamil diluar nikah & 24 & 96 & 1 & 4 \\
\hline 5 & Aborsi bisa mengakibatkan kematian bagi remaja putri & 20 & 80 & 5 & 20 \\
\hline 6 & $\begin{array}{l}\text { Perilaku seks bebas tidak sesuai dengan ajaran agama dan } \\
\text { nilai-nilai moral }\end{array}$ & 25 & 100 & 0 & 0 \\
\hline 7 & Menyukai lawan jenis adalah hal yang wajar bagi remaja & 22 & 88 & 3 & 2 \\
\hline 8 & $\begin{array}{l}\text { Perilaku seks bebas bisa mengakibatkan menderita } \\
\text { penyakit menular seksual }\end{array}$ & 25 & 100 & 0 & 0 \\
\hline 9 & $\begin{array}{l}\text { Kuman yang terdapat di vagina/kemaluan seorang wanita } \\
\text { karna mengalami penyakit menular seksual }\end{array}$ & 25 & 100 & 0 & 0 \\
\hline 10 & $\begin{array}{l}\text { Herpes/gatal yang bisa pecah pada kemaluan merupakan } \\
\text { sebagai salah satu jenis penyakit menular seksual }\end{array}$ & 20 & 80 & 5 & 20 \\
\hline 11 & HIV/AIDS dapat ditularkan melalui hubangan seksual & 24 & 96 & 1 & 4 \\
\hline 12 & $\begin{array}{l}\text { Infeksi menular seksual dapat ditularkan selain melalui } \\
\text { hubungan seksual }\end{array}$ & 18 & 72 & 7 & 28 \\
\hline 13 & $\begin{array}{l}\text { Demam, keringat dimalam hari, diare berkelanjutan, } \\
\text { kelelahan, dan batuk terus menerus serta penurunan berat } \\
\text { badan yang berkelanjuan adalah gejala HIV/AIDS }\end{array}$ & 14 & 56 & 11 & 44 \\
\hline 14 & $\begin{array}{l}\text { Jika mengalami keputihan yang tidak wajar harus segera } \\
\text { diperiksakan ke fasilitas pelayanan kesehatan }\end{array}$ & 24 & 96 & 1 & 4 \\
\hline 15 & $\begin{array}{l}\text { Kulit di sekitar kemaluan lecet, memudahkan penularan } \\
\text { infeksi HIV }\end{array}$ & 23 & 92 & 2 & 8 \\
\hline 16 & HIV/AIDS dapat menyebabkan kematian & 20 & 80 & 5 & 20 \\
\hline 17 & $\begin{array}{l}\text { Pendidikan kesehatan angat diperlukan untuk pencegahan } \\
\text { peyakit menular seksual }\end{array}$ & 22 & 88 & 3 & 12 \\
\hline 18 & $\begin{array}{l}\text { Penyakit kencing bernanah adalah jenis infeksi menular } \\
\text { seksual }\end{array}$ & 19 & 76 & 6 & 24 \\
\hline
\end{tabular}




\section{Pembahasan}

Hasil penelitian diperoleh data karakteristik remaja anak jalanan adalah mayoritas suku Padang (76\%), pendidikannya SMP (54\%), ayah dan ibu masih ada (ayah $80 \%$ dan ibu 92\%), pendidikan orang tua SMA $80 \%$. Hasil kuesioner pengetahuan masih ada (44\%) anak jalanan belum menjawab benar pertanyaan tentang gejala HIV/AIDS. Gejala HIV/AIDS yaitu berupa demam, keringat dimalam hari, diare berkelanjutan, kelelahan, dan batuk terus menerus serta penurunan berat badan. Mereka juga belum semua menjawab benar pada pertanyaan penyakit kencing bernanah adalah jenis infeksi menular seksual $(24 \%)$, cara penularan penyakit menular seksual (20\%); dan HIV/AIDS dapat menyebabkan kematian (20\%).

Pendidikan seks perlu dilakukan untuk meningkatkan pengetahuan remaja tentang bahaya seks bebas, infeksi menular seksual misalnya HIV/AIDS. Perilaku seks bebasremaja pernah melakukan kissing, necking, petting, hingga intercourse yang dilakukan dengan pasangan kekasih dan dengan pekerjaseksual [15].

Dampak yang ditimbulkan dari prilaku seks bebas sangat beragam dari mulai berjangkitnya penyakit kelamin, aids dan munculnya mafia perdagangan wanita. Hubungan seks pranikah umumnya berawal dari masa pacaran. Pada masa pacaran ini hubungan intim mulai dilakukan kalangan remaja. Baik pelajar, mahasiswa, pemuda-pemudi tidak sekolah, mereka tinggal di kota atau di desa. Hal ini disebabkan remaja anak belum pernah mendapatkan informasi ini baik dibangku sekolah maupun dari orang tuanya [7].

Pemahaman remaja akan kesehatan reproduksi menjadi bekal remaja dalam berperilaku sehat dan bertanggung jawab. Remaja belum semua memperoleh informasi yang cukup dan benar tentang kesehatan reproduksi terutama anak jalanan [20]. Keterbatasan pengetahuan dan pemahaman ini dapat membawa remaja ke arah perilaku berisiko. Anak jalanan ini perlu diberi pengertian, bimbingan dan dukungan dari lingkungan disekitarnya agar dalam sistem perubahan tersebut terjadi pertumbuhan dan perkembangan yang sehat sedemikian rupa sehingga kelak remaja menjadi manusia dewasa yang sehat secara jasmani, rohani dan sosial.Penelitian juga membuktikan bahwa terdapat Ppngaruh penyuluhan tentang bahaya seks bebas terhadap pengetahuan remaja tentang seks bebas Di SMA Negeri Binsus 9 [3].

Tujuan pendidikan seks adalah untuk menghasilkan manusia-manusia dewasa yang dapat menjalankan kehidupan yang bahagia karena dapat menyesuaikan diri dengan masyarakat dan lingkunganya serta bertanggung jawab terhadap dirinya dan terhadap orang lain. Faktor yang mempengaruhi prilaku sex bebas yaitu faktor lingkungan, remaja sekarang sangat mudah dipengaruhi oleh lingkungan sehingga faktor lingkungan sangat berpengaruh sekali didalam perkembangan remaja yang bisa membuat remaja terjerumus kedalam dunia seks bebas $\left({ }^{3}\right)$. Konsekuensi perilaku seks berisiko tersebut, selain melanggar nilai dan norma agama, juga adat istiadat yang berlaku di Indonesia [7].

Dampak perilaku seks berisikoterkena infeksi menular seksual seperti penyakit ghonorea bagi pria. Perempuan yang melakukannya di bawah umur umumnya mengalami perasaan trauma hingga depresi. Kehamilan ditimbulkan dari hubungan seks tersebut berbahaya bagi organ reproduksi perempuan. Dampak lain perilaku seks berisiko anak muda terhadap kesehatan reproduksi, antara lain kehamilan yang tidak diinginkan (unwanted pregnancy). Kehamilan yang tidak diinginkan membawa anak muda pada dua pilihan, melanjutkan kehamilan atau menggugurkannya.

Hamil dan melahirkan dalam usia muda merupakan salah satu faktor risiko kehamilan yang tidak jarang membawa kematian ibu. Terjadinya perdarahan pada trimester pertama dan ketiga, anemi merupakan komplikasi yang sering terjadi pada kehamilan anak muda. Kehamilan di usia muda juga berdampak pada anak yang dikandung, kejadian berat bayi lahir rendah (BBLR) dan kematian perinatal sering dialami oleh bayi-bayi yang lahir dari ibu usiamuda [1][18].

Perilaku seks berisiko terhadap kesehatan reproduksi adalah tertular infeksi menular seksual termasuk HIV/AIDS. Mencegah dan mengobati IMS dapat mengurangi resiko penularan HIV melalui hubungan seks [9]. Anak muda sering kali melakukan hubungan seks 
yang tidak aman dengan kebiasaan berganti-ganti pasangan dan melakukan anal seks menyebabkan anak muda semakin rentan untuk tertular penyakit menular seksual seperti sifilis, gonore, herpes, klamidia, dan AIDS. Dari data yang ada menunjukkan bahwa diantara penderita atau kasus HIV/AIDS 53\% berusia antara 15-29 tahun [7].

Konsekuensi psikologis dari perilaku seks bebas adalah Kodrat untuk hamil dan melahirkan menempatkan anak muda perempuan dalam posisi terpojok yang sangat dilematis. Dalam pandangan masyarakat, anak muda perempuan yang hamil merupakan aib keluarga yang melanggar norma-norma sosial dan agama. Penghakiman sosialini tidak jarang meresap dan terus tersosialisasi dalam dirinya. Perasaan bingung, cemas, malu, dan bersalah yang dialami pelajar setelah mengetahui kehamilannya bercampur dengan perasaan depresi, pesimis terhadap masa depan yang kadang disertai dengan rasa benci dan marah baik kepada diri sendiri maupun kepada pasangan, dan kepada nasib yang membuat kondisi sehat secara fisik, sosial, dan mental yang berhubungan dengan sistem, fungsi, dan proses reproduksi anak muda tidak terpenuhi [7].

Kader kesehatan mempunyai peran besar dalam upaya mewujudkan derajat kesehatan masyarakat yang optimal [20]. Kader kesehatan remaja adalah remaja yang dipilih atau secara sukarela mengajukan diri untuk ikut melaksanakan upaya pelayanan kesehatan terhadap diri sendiri, teman, keluarga serta masyarakat [10]. Pembinaan kader kesehatan reproduksi remaja dilakukan untuk memberikan informasi dan pengetahuan yang berhubungan dengan perilaku hidup sehat bagi remaja, di samping juga untuk mengatasi masalah yang ada [1][10].

\section{Kesimpulan}

Penelitian membuktikan bahwa pengetahuan anak jalanan tentang bahaya seks bebas dan infeksi menular seksual setelah dilakukan penyuluhan kesehatan oleh kader remaja anak jalanan mayoritas baik. Saran kepada pimpinan KOPA agar melanjutkan pembinaan kader remaja anak jalanan ini dan tetap melaksanakan kegiatan penyuluhan secara rutin kepada anak jalanan lainnya.

\section{Ucapan Terima Kasih}

Hasil penelitian ini merupakan salah satu luaran pelaksanaan pengabdian kepada masyarakat dengan dana NON PNBP Universitas Sumatera UtaraSesuai dengan Surat Perjanjian Penugasan Pelaksanaan Pengabdian kepada Masyarakat Program Mono Tahun RegulerTahun Anggaran 2020Nomor : 287/UN5.2.3.2.1/PPM/2020, Tanggal 9 Juni 2020, untuk itu kami sampaikan terima kasih kepada bapak rektor, Wakil rektor III dan ketua LPPM USU.

\section{Referensi}

[1] Andyantoro.I., Kumalasari.I. (2012). Kesehatan Reproduksi untuk Mahasiswa Kebidanan dan Keperawatan. Jakarta: Salemba Medika

[2] Asriwati., Irawati. (2019) Buku Ajar Antropologi Kesehatan dalam Keperawatan. Yogyakarta. Deepublish.

[3] Bachruddin. W., Kalalo. F., Kundre.R. (2017). Pengaruh penyuluhan tentang bahaya seks bebas terhadap pengetahuan remaja tentang seks bebas di SMA negeri Binsus 9 Manado. e-journal Keperawatan (e-Kp) Sam Ratulangi. Volume 5 Nomor1 , Mei 2017

[4] Banun, F.O.S., Setyorogo. (2012). Faktor-Faktor Yang Berhubungan Dengan Perilaku Seksual Pranikah Pada Mahasiswa Semester V STIKes X Jakarta Timur 2012. Jurnal Ilmiah Kesehatan, 5(1):12-19.

[5] Depkes RI, 2012. Pusat data dan informasi Kementrian Kesehatan RI. Situasi Kesehatan reproduksi Remaja. Jakarta: Depkes RI.

[6] Desmita, (2012). Psikologi Perkembangan. Bandung : Remaja Rosdakarya

[7] Kasim. F. (2014). Dampak Perilaku Seks Berisiko terhadap KesehatanReproduksi dan Upaya Penanganannya (Studi tentang Perilaku Seks Berisiko pada Usia Muda di Aceh). Jurnal Studi Suami. Vol 3 (1). Mei 2014 
[8] Kementrian Kesehatan RI (2014). Peraturan Mentri Kesehatan RI Nomor 25 Tahun 2014 tentang upaya kesehatan anak : Jakarta. Nomor 25 tahun 2014

[9] Kementrian Kesehatan RI (2015). Pedoman Nasional Penanganan Infeksi Menular Seksual. Jakarta: Kemenkes RI.

[10] Kementrian Kesehatan RI (2018). Buku KIE Kader kesehatan Remaja. Jakarta. Kemenkes.RI

[11] Muslimin, A. (2013). Karakteristik Anak Jalanan dalam Interaksi Sosial di Kota Makassar. Vol 7. No 1. Diakses melalalui https://journal.uin-alauddin.ac.id. pada 13 Januari 2020.

[12] PKPA. (2011). Situasi Anak Jalanan Kota Medan. PKPA. Medan.

[13] PP Nomor 44 Tahun 2017 tentang anak jalanan

[14] Pusat Kajian Perlindungan Anak (2018). PendidikanAnak Jalanan. Melalui kompasiana. Diakses melalui https://www.kompasiana.com. Pada 22 Desember 2019.

[15] Rahadi .D.S., Indarjo.S. (2017). Perilaku Seks Bebas pada Anggota Club Motor X Kota Semarang Tahun 2017. Journal of Health Education 2 (2) 2017

[16] Setiari NM. (2015). Pengetahuan dan sikap personal hygine organ reproduksi remaja putri jalanan dikota denpasar, Skripsi S1 Fakultas Ilmu Keperawatan, Fakultas Kedokteran dan Ilmu Kesehatan, Universitas Udayana Denpasar.

[17] Soetjiningsih. (2004). Tumbuh kembang remaja dan permasalahannya. Jakarta: Agung Seto.

[18] Suyanto.B. (2010). Masalah Sosial Anak. Jakarta : Kencana.

[19] Unicef. (2003). Anak Jalanan. Diakses melalui https://id.m.wikipedia.org. pada 12 Desember 2019.

[20] Yulifah.R., Yuswanto.T.J.A. (2012). Konseling dalam Kebidanan. Jakarta : Salemba Medika 